\title{
Analysis of Bus Passenger Demand and Supply: Case Study on Western Province, Sri Lanka
}

\author{
Thivya Amalan \\ University of Moratuwa
}

\begin{abstract}
:
The Sri Lanka Transport Board (SLTB) and private bus companies are major operators of bus transportation, which operates roughly 680 intra-provincial bus routes and 400 inter-provincial bus routes in the Western Province according to the bus route information from the National Transport Commission (NTC, 2012) . Buses carried about $47 \%$ of passengers crossing the Colombo Municipal Council (CMC) boundary in 2013. The number of buses on the seven (7) major radial corridors carries more bus passengers than other roads in the Western Province. Kandy, Galle and Malabe Road corridors are the highest followed by High Level, Negombo, Horana and Low Level Road corridors. This research paper is an attempt to analyse the bus passenger demand and supply on seven major corridors connecting Western Province boundaries. The impact of the passenger demands and volumes from the seven major corridors and the traffic speed are the main outcome of this analysis. The present bus traffic information and the impact of the traffic congestion due to the high traffic flow on major corridors are discussed in the analysis. The research focuses on alternative solutions and the importance of integrating other public transport modes to cater the demand from the major seven corridors for the better utilisation of public transport inside the Western Province boundaries.
\end{abstract}

Keywords: Public Transport, Transport Supply, Transport Demand, Traffic Flow, Traffic Congestion

\section{Introduction}

Buses are the core transport mode in Sri Lanka. However, the declining passenger bus usage pattern was observed in the recent past. The statistical data shows that the bus passengers crossing the CMC boundary were $65 \%$ in 1985, $57 \%$ in 1995, $55 \%$ in 2004 and $47 \%$ in 2013. The Sri Lanka Transport Board (SLTB) and private bus companies operates their services roughly on 680 intra-provincial bus routes and 400 interprovincial bus routes in the Western Province according to the bus route information from the National Transport Commission (CoMTrans, 2013). It is evident that most of the buses operated in the Western Province have one of their trip destination end in Pettah where three bus terminals are located namely Central SLTB, Bastian Mawatha and Gunasinghepura.

Majority of the Colombo City bound traffic use the major seven road corridors namely Kandy Road (A1), Galle Road (A2), Puttalam/Negombo Road (A3), Low Level Road (AB10), High Level Road (A4), Horana Road (B84), and Malabe Road (Figure 1)., These road corridors are highly congested especially during the peak hours due to the heavy traffic flows. Subsequently, inadequate capacity of the road causes significant reduction on average velocity of the overall traffic stream on these road corridors.

his research focuses on the behaviour of bus passenger demand and supply of main seven road corridors within the Western Province and considers how the demand could be supplied during the peak hours. Also 
this paper focuses on the oversupply nature of the bus transportation system during the off peak hours and what are the alternatives to utilising such supplies effectively in the overall bus transport system. The analysis has covered the mode share behaviour on these corridors to evaluate the efficiency of bus operations and to propose requirements of rail based transportation to reduce the congestion on the road corridors.

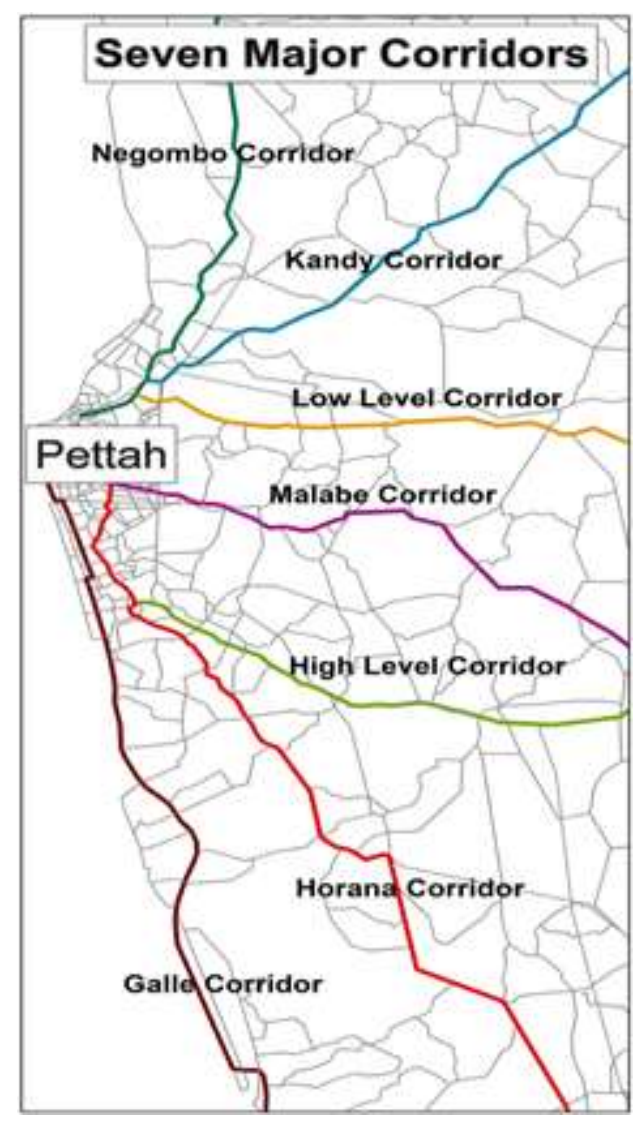

Figure 1 - Seven Major Corridors

\section{Objective}

The main objectives of this research study are;

- To evaluate present bus passenger demand and supply during the peak and off peak hours on seven major bus routes.

- To quantify the impact of other motorized road transport supply modes to the bus passenger demand and supply.

- To analyse the impact on the travel speed of overall vehicle stream.

To propose possible solutions to mitigate the supply inadequacy during the peak hour and excess supply during the off peak hour at seven road corridors.

\section{Literature Review}

Seven transport corridors have been identified as most important corridors taking transport volume, urbanization level, and population density into considerations. Over one million people enter the Colombo city each day, using seven corridors namely Kandy Road (A1) Galle Road (A2), Puttalam Road (A3), Low Level Rpad (AB10), High Level Road (A4), Horana Road (B84), and Malabe Road. Over 174,000 and 
157,000 persons enter the city via Galle Road and Malabe Road corridors [2]. The load factor (demand/supply) of public buses operating on major city corridors stay above 1 for most part of the day and exceeds 1.5 during the peak periods [3]. The existing Colombo - Kandy road (A1) is one of the most frequently used and demanding road in the country. It is responsible for connecting not only the Central Province but also the Eastern, Northern and North Central Provinces with the capital city Colombo [4]. Complete deregulation might lead to a greater concentration of vehicles at the times and locations where demand is highest but it would also tend to some of the perceived problems, such as overcrowding at particular times and locations are the result of the way in which the current regulatory system works [5]. Although traffic congestion has long been identified as a problem, it continues to worsen in almost all urban areas. Since 1997 the speed of vehicles during rush hours has reduced from $32 \mathrm{~km}$ per hour to $8 \mathrm{~km}$ per hour for a $13 \mathrm{~km}$ distance from Colombo along Kandy, Galle, Ratnepura, Negambo, Kaduwela and Horana Road. Car ownership in many Asian cities is doubling every 3 to 7 years. Annual new registration of vehicles is over 300,000 in Sri Lanka. 50\% of such registrations are motorcycles and only $1 \%$ constitutes public passenger transport [1].

\section{Methodology}

Screen line survey (SLS) and manual classified vehicle count survey (MCC) data has been used to analyze the demand and supply of bus passengers at seven major corridors of the Western Province. The quantitative analysis has been done using these empirical data. The screen line survey has been conducted to observe traffic volume at specified cross boundaries at the major road corridors. MCC survey has been used to obtain the number of vehicles by hour band by mode by direction. The survey locations has been selected based on the major roads which are going through the CMC boundary and passes through $5 \mathrm{~km}$ and $10 \mathrm{~km}$ peripherals. The survey was conducted in 67 locations in western province to analyze the vehicle movements for major corridors.

The bus demand was analyzed from the screen line survey by using three separate peripherals namely;

1. Boundary of Colombo Municipal Council (CMC)

2. $\mathrm{CMC}+5 \mathrm{~km}$

3. $\mathrm{CMC}+10 \mathrm{~km}$

The screen line survey was conducted on a weekday either for 16 hours (6:00 AM to 10:00 PM) or 24 hours (6:00 AM to 6:00 AM of the following day) depending on the survey location. The survey was conducted for both directions and using manual traffic counters or tally marks. The surveyors recorded the number of vehicles on the survey sheet every hour. The daily traffic estimates for locations of 16 hours count has been expanded using the night time factors estimated from 24 hour survey traffic data.

The traffic demand and supply analysis considered only from 6:00- 22:00 hrs in this report due to the availability of such data. Bus passenger loading rate is calculated from the boarding and alighting data from screen line survey. The private vehicles estimates has been done by using MCC data between 6:0022:00hours. All surveys are conducted in year 2013 and road settings used for analysis are same as the 2013 road network.

Traffic speed analysis has been completed using the travel speed survey data along the seven road corridors between Colombo and Western Province Boundary. Travel time survey was conducted for both the morning and evening peak hours.

\section{Data Analysis}


Traffic demand and supply has been analysed across three peripherals separately for seven road corridors (Figure 2).

1. Along the $\mathrm{CMC}$ boundary

2. $5 \mathrm{~km}$ from the CMC boundary

3. $10 \mathrm{~km}$ from the $\mathrm{CMC}$ boundary

The data analysis was carried out at all selected points from the three peripherals for the peak hours (6:009:00 and 17:00-20:00) and off peak hours (9:00-17:00 and 20:00-22:00) in seven main road corridors. The data also focused on the bus passenger loading rate in the peak hour and off peak hour.

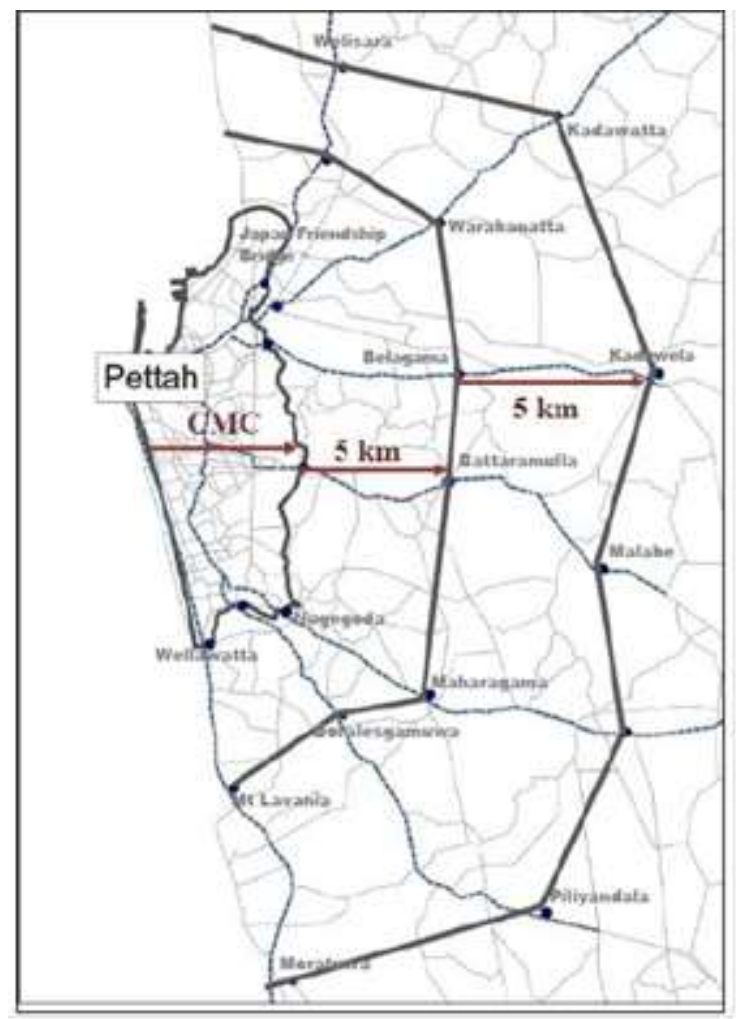

Figure 2 - Three Levels of Demand Analysis Peripherals

The bus passengers' behaviour at the seven major road corridors has been deliberated by concentrating the transport aspects such as bus passenger demand and supply during peak and off peak hour, mode share of private and buses, and a comparative analysis of other roads with the road corridors in Western Province and the travel speed along the road corridors.

\subsection{Peak Hour and Off Peak Hour Demand and Supply}

The Figure 3 shows the peak hour bus passengers demand and supply at the CMC boundary at all seven bus routes. In Malabe Road, Horana Road and Low Level Road all three peripherals have higher demand and the higher supply deficiency for buses during the peak hour (Figure 3, $5 \& 7$ ). This may be due to the insufficient integration of other public transport supply modes such as railway and also the lack of alternative public transport routes and under capacity of the present road network as well. 


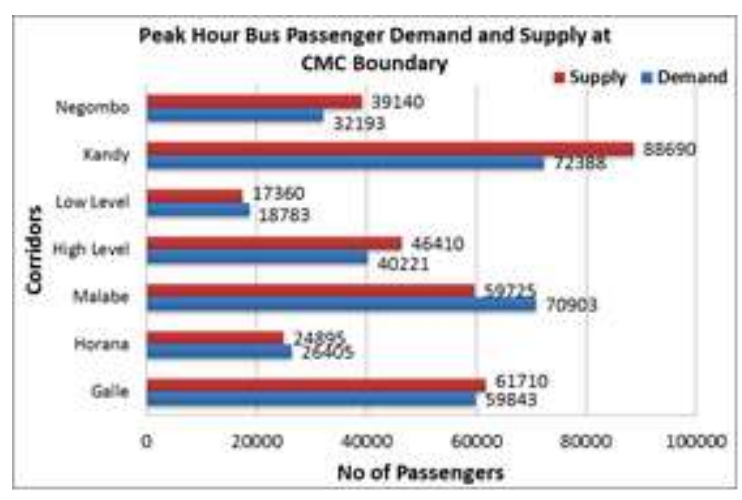

Figure 3 -Peak Hour Bus Passengers Demand and Supply at CMC boundary

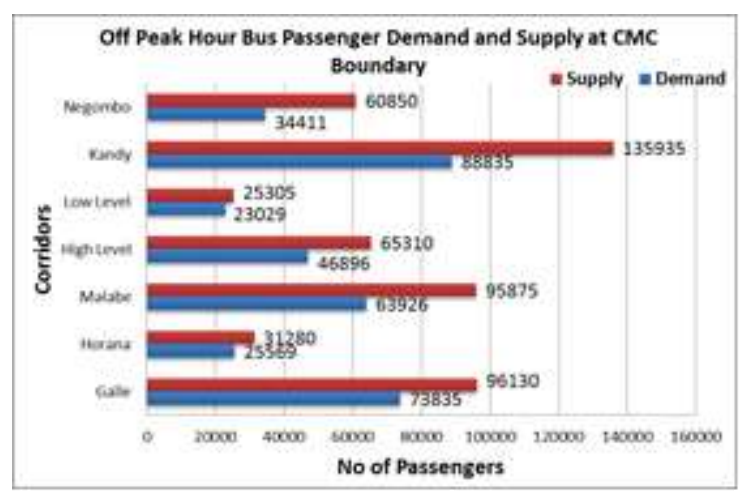

Figure 4 - Off Peak Hour Bus Passengers Demand and Supply at CMC boundary

Malabe transport corridor has no railway line and it is the main corridor connecting the eastern suburban residential areas and the commercial hub of Colombo. The largest share of the private vehicles about $94 \%$ (National Transport Statistics, 2014) can be identified on this corridor. In the Figure 5 and Figure 7, it can be observed that the supply deficiency is evidence at $\mathrm{CMC}+5 \mathrm{~km}$ and $\mathrm{CMC}+10 \mathrm{~km}$ peripherals during peak hour. However, at the $\mathrm{CMC}+5 \mathrm{~km}$ peripheral (Figure 5), the supply deficiency is much higher than the other peripherals due to the higher number of trip attraction and distribution. Moreover, the excess supply can be identified at three peripherals during the off peak hour (Figure 4 and 8). In addition, the bus loading rate is also much lower than $75 \%$ for all three peripherals (Table 1 ).

Low Level corridor has excess demand at CMC (Figure 3) and CMC $+5 \mathrm{~km}$ (Figure 5) than the CMC $+10 \mathrm{~km}$ (Figure 7) indicating the increased loading towards the Colombo City. Due to the existing 2 lanes substandard road capacity, the road is so congested during the peak hour and there is no railway mode option available along this corridor. The greater bus passenger loading rate can be observed at Low Level Road during the peak hour (Table 1). Off peak hour, supply and demand are at the optimum level at all the boundaries (Figure 4, $6 \& 8$ ). Buses are not fully utilised during the off peak hour and loading rate is less than $85 \%$ at three peripherals (Table 1 ). 


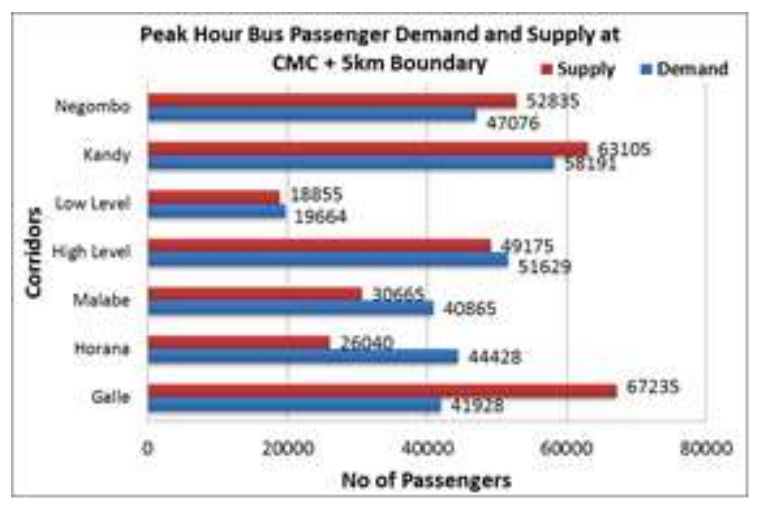

Figure 5 - Peak Hour Bus Passengers Demand and Supply at CMC +5km boundary

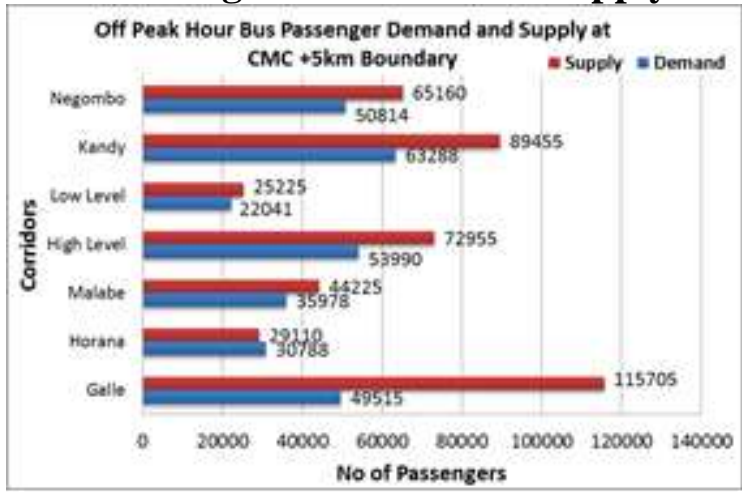

Figure 6 - Off Peak Hour Bus Passengers Demand and Supply at CMC+5km boundary

Table 1: Peak Hour and Off Peak Hour Bus Passenger Loading Rate (\%)

\begin{tabular}{|c|c|c|c|c|c|c|}
\hline \multirow{2}{*}{$\begin{array}{c}\text { Road } \\
\text { Corridors }\end{array}$} & \multicolumn{2}{|c|}{ CMC } & \multicolumn{2}{c|}{ CMC+5 km } & \multicolumn{2}{c|}{ CMC+10 km } \\
\cline { 2 - 7 } & Peak & $\begin{array}{c}\text { Off- } \\
\text { Peak }\end{array}$ & Peak & $\begin{array}{c}\text { Off- } \\
\text { Peak }\end{array}$ & Peak & $\begin{array}{c}\text { Off- } \\
\text { Peak }\end{array}$ \\
\hline Galle & 95 & 75 & 81 & 83 & 98 & 76 \\
\hline Horana & 120 & 80 & 140 & 86 & 121 & 83 \\
\hline Malabe & 94 & 62 & 107 & 74 & 119 & 55 \\
\hline $\begin{array}{c}\text { High } \\
\text { Level }\end{array}$ & 98 & 72 & 106 & 76 & 109 & 70 \\
\hline $\begin{array}{c}\text { Low } \\
\text { Level }\end{array}$ & 120 & 85 & 102 & 71 & 107 & 89 \\
\hline Kandy & 93 & 68 & 96 & 68 & 113 & 95 \\
\hline Negombo & 105 & 68 & 105 & 83 & 110 & 85 \\
\hline
\end{tabular}

Horana corridor has supply deficiency along three peripherals and highest deficiency is happening across the $\mathrm{CMC}+5 \mathrm{~km}$ peripheral limit. This may be due to the trip attraction and generations across $\mathrm{CMC}+5 \mathrm{~km}$ is much higher than the other zones. Also the capacity of the Horana corridor is much low and it has only two lanes capacities at present. The off peak hour supply and demand behaviour is same as the Low Level road and loading rate is lower than the $85 \%$. 


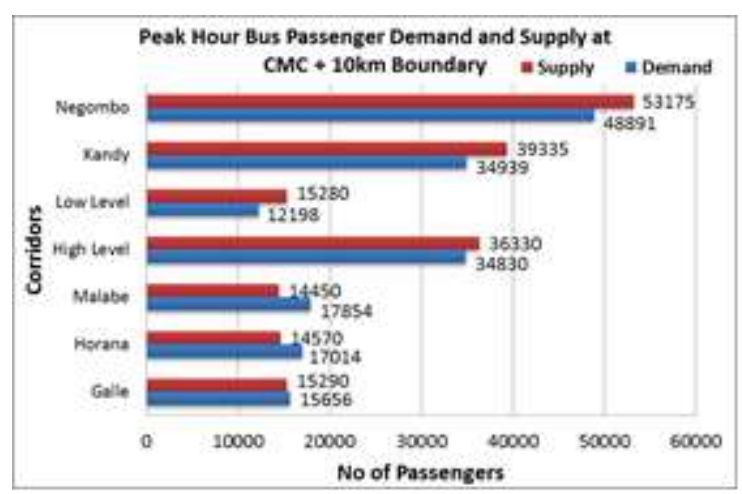

Figure 7- Peak Hour Bus Passengers Demand and Supply at CMC +10km boundary

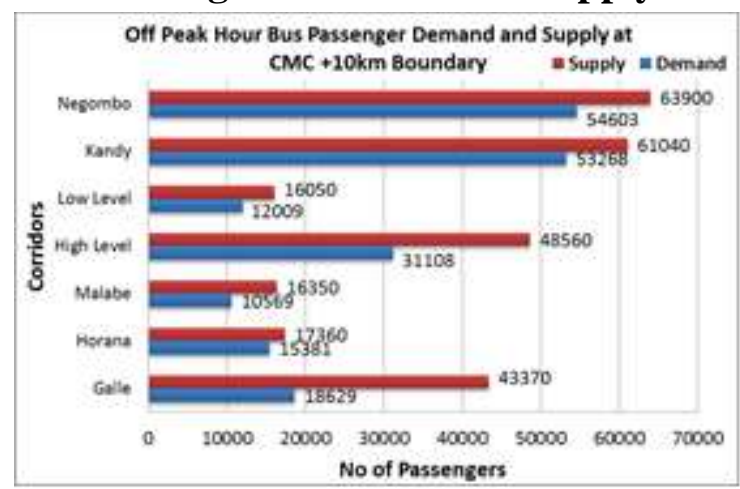

Figure 8 - Off Peak Hour Bus Passengers Demand and Supply at CMC+10km boundary

Negombo Road corridor consists of Puttalam Railway line, A03 arterial road with 4 lanes capacities, and Colombo-Katunayake Expressway (E03). Galle Road corridor consists of the Coastal Railway line, A02 arterial of 4 lanes and Marine Drive with two lanes and the future provision for extension up to Ratmalana. High Level Road contains Kelani-Valley Railway line and A04 arterial road with 4 lanes capacities. Kandy Road corridor entails of Main Railway line, with 4 lane capacity of A01 arterial road, with future provision for Northern expressway. It may be due to the increased road capacities and provision of recent expressways facilities and mode integrations, where the demand and supply for the above three corridors is at an adequate level. However, the traffic density during the peak hours is much high and it can be evitable that high traffic flows are observed along these corridors than the other road corridors

Conversely, the Galle corridor has higher impact on the demand and supply during the off peak hours. It has utilized only $43 \%$ of the bus capacity at CMC+5km and $10 \mathrm{~km}$ boundaries (Figure $4,6 \& 8$ ). The loading rate is also less than $80 \%$ (Table 1). Yet, the supply and demand are well matched at the CMC boundary. High Level Road is also having excess supply (Figure 4, $6 \& 8$ ) compare to the demand. The loading level is also less than the $75 \%$ (Table 1) during the off peak hour.

\subsection{Road Passenger Mode Share (Bus Passenger vs Private Mode Users)}

The mode share by both private vehicle passengers and the bus passengers has been compared at all said analysis peripherals and given in Figures 9, 10 and 11.

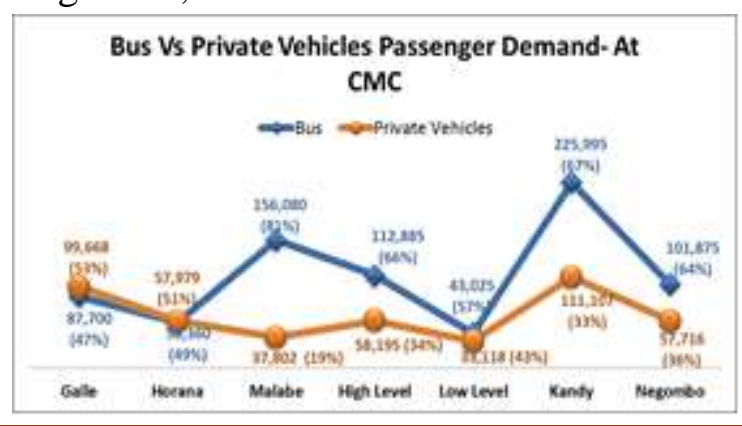


Figure 9 - Daily Passenger Mode Share- At CMC

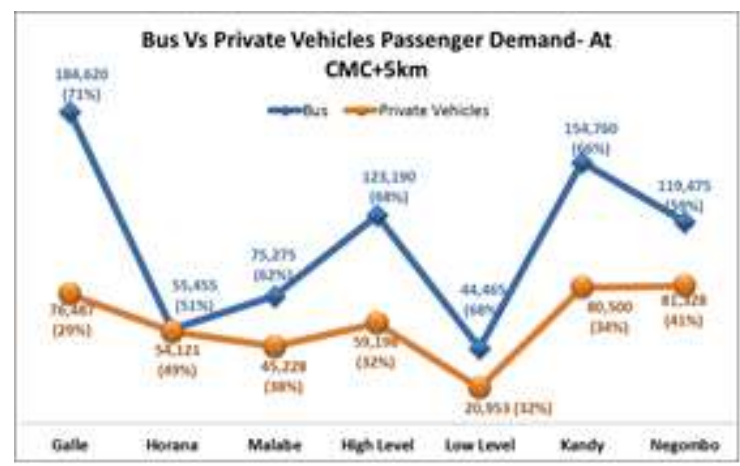

Figure 10 - Daily Passenger Mode Share- At CMC+5 km

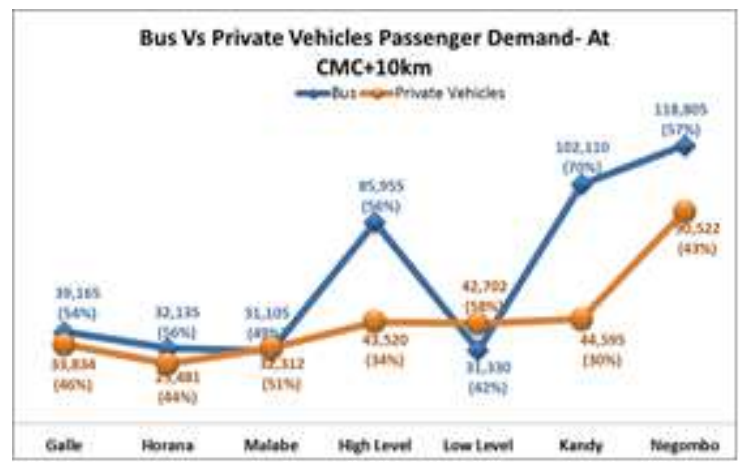

Figure 11 - Daily Passenger Mode Share- At CMC+10 km

The analysis results from Figure 9 to 11 show that the percentages of the passengers using private vehicles for all the corridors are significantly high. Horana Road and Low Level Road corridor has higher number of private vehicle share for the all three peripherals. As a result both road corridors seem to be very much congested even during the off peak hours. Kandy corridor has the lower private vehicle share compare to other road corridors due the nature of the high demand for long distance bus passengers.

Galle road corridor has higher usages of private vehicles inside the CMC boundary than the bus users. This is the main reason for the traffic congestion happening in the peak hours. It can be evitable that the capacity of the Galle Road corridor is not adequate the demand of users. Moreover the immediate plans have to be implemented inside the CMC to avoid traffic congestions and bottleneck. Despite there are only about $30 \%$ $35 \%$ of private mode users in High Level and Kandy Road corridors, bus passengers are gradually declining along these corridors too. 


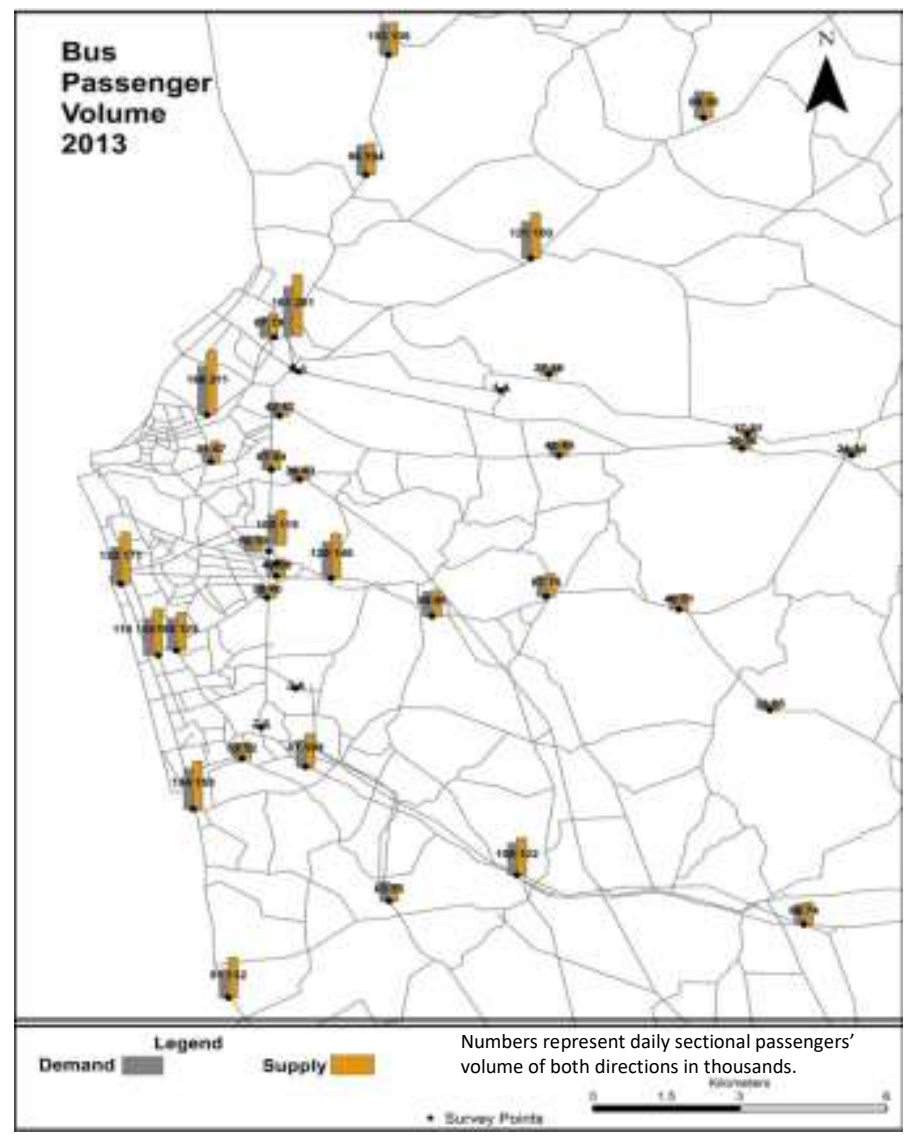

Figure 12 - Daily Bus Passenger Demand and Supply at Main Corridors

The Figure 12 clearly shows the overall daily demand and supply for the bus mode at major corridors. The results show that both demand and supply is significantly high along the seven corridors than the other road corridors in the Western province. Especially Negombo Road, Galle Road, Kandy Road and High Level Road corridors have the highest bus passenger demand and supply. As a result of the traffic congestion the travel speed for the buses and the other modes are significantly low. For Sri Lankan driving habits and vehicles composition the average speed can be $25 \mathrm{~km} / \mathrm{h}$. However travel speeds of surrounding areas of major seven corridors are mostly less than $20 \mathrm{~km} / \mathrm{h}$ and some sections are observed less than $10 \mathrm{~km} / \mathrm{h}$ during morning and evening peak hours (Figure 13). Paliyagoda, Maradhana, Orugodawatta, Thunmulla and Borella Junctions are having less than $10 \mathrm{~km} / \mathrm{h}$ travel speed as they handle large traffic volumes as the major intersections. The travel speed data indicates that the congestion takes place near the entry to the CMC boundary compared to the other sections. The traffic congestion inside the CMC boundary is also less than these sections and hence has a very significant impact for commercial activities in the CBD. 


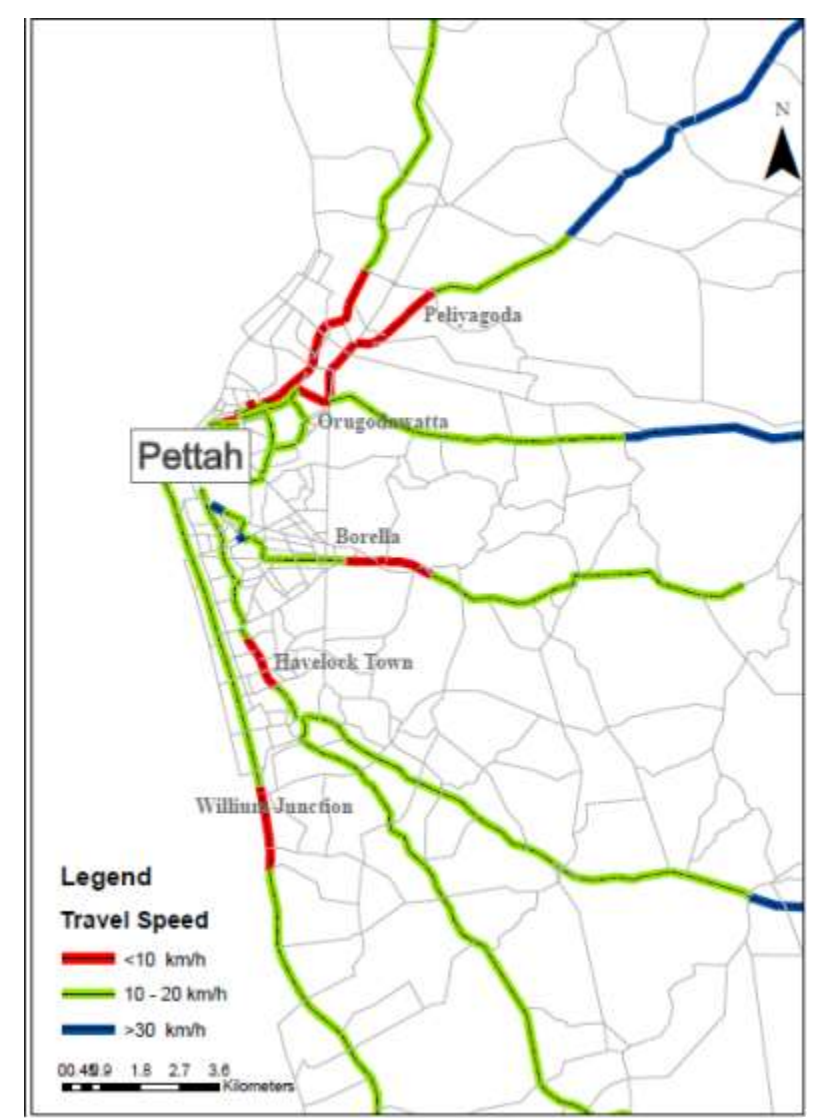

Figure 13: Peak Hour Travel Speed

\section{Recommendations}

According to the data analysis, it is evident that public transportation development is needed to reduce the traffic congestions along the corridors. The analysis also disclosed that poor performance of the public bus transport has become a major reason for the traffic congestion during the peak hour.

With the aim of mitigating these issues, new modes of public transport such as BRT, monorail and railway electrifications with traffic control and management should be focused on. Some proposals for these corridors are analysed separately to find the efficient solutions to address the issues at industrial level at present. Malabe Road, Horana Road and Low Level Road corridors need more attention than other road corridors. These corridors have now reached their maximum capacities and needed development should be considered to avoid traffic congestions and bottle necks during the peak hour. Due to the higher share of the private vehicles the roads are congested and the road space to operate the buses is inadequate during the peak hour. Especially Horana Road and Low Level Road is still at 2 lanes capacities and road widening should be focus in near future for the entire length. The above three corridors also need to focus on rail based transport modes to cater the peak hour demand in near future and avoid economic losses due to the congestion.

The analysis also shows the excess supply at off peak hour. In Malabe Road, Galle Road, Kandy Road, Negombo Road and High Level Road have the oversupply of buses during the off peak and it is to be well managed through the adequate scheduling and timing for these routes. The best solutions are re-routing and reduce the frequency of the buses during the off peak hour. Re-routing is one of the best solutions to serve congested areas and rural areas by shifting the bus fleet from over supplied area during the off peak hour. Private buses are owned by several individual bodies and controlling and managing the private bus fleet is also a difficult task as per the present experience of this industry. However, SLTB (Sri Lanka Transport Board) can focus on the re-routing of their buses during the off peak hour. 
Transport demand management tools like redistribution of excess supply of buses, improvement of public and para transit, increase the mobility of existing highways and introducing new public transport policies are important factors to be considered in future transport planning in western Province. The above factors should be considered to increase the travel speed to be maintained not less than $25 \mathrm{~km} / \mathrm{h}$ along the corridors. Improvement in public transport alone appears to be incapable of inducing sufficient mode shift in favour of public transport. It must be clearly indicate that improvement in service quality need to be focus to increase public transport while keeping stringent government policies for car importance and utilization in Sri Lanka in future.

\section{Acknowledgement}

The authors wish to acknowledge with appreciation the assistance extended by the Team Members of the JICA Study Team for CoMTrans Project which was the largest transport study carried out in Colombo Metropolitan Region, from year 2012 -2015 under the purview of Ministry of Transport of Sri Lanka.

\section{References}

1. Asoka Abeygunawardana., "The Solution: Low carbon economy", Energy Forum, n.a

2. Chaminda Perera 2013, 'Urban transport master plan for next 20 years ', Daily News 11 December. Available from: < http://www.dailynews.lk/?q=local/urban-transport-master-plan-next-20-years>. [05 May 2015].

3. Janaka Weerawardena.," Reduction of Traffic Congestion in Colombo City by Improving Public Bus Transport", Economic Review, 2011

4. Wu, B., Maekawa, K., \& Okamura, H., "Contact Density Model for Stress Transfer Across Cracks in Concrete”, J. Faculty of Eng., The University of Tokyo, Vol. 11, No. 01, March, 1989, pp. 9-52.

5. Ken Gwilliam, "Study of Urban Public Transport Conditions in Sri Lanka", 2015http://www.iesl.lk/, Visited, 14th June 2011

6. Ministry of Highways and Road Development," Colombo - Kandy Expressway: Information for investors", 2011

7. Tissa U Liyanage et all, "A Comparison of the Characteristics of Urban and Rural Bus Transport in Sri Lanka - A Case Study” Annual sessions IESL, 2008 